ZOOLOGIA 27 (2): 305-308, April, 2010

doi: $10.1590 /$ S1984-46702010000200015

\title{
Brazilian species of Gadila (Mollusca: Scaphopoda: Gadilidae): rediscovery of Gadila elongata comb. nov. and shell morphometrics
}

\author{
Carlos H. S. Caetano1, 4; Victor Scarabino² \& Ricardo S. Absalão³
}

\author{
${ }^{1}$ Departamento de Zoologia, Universidade Federal do Estado do Rio de Janeiro. Avenida Pasteur 458, sala 309, Urca, \\ 22290-240 Rio de Janeiro, Rio de Janeiro, Brazil. \\ ${ }^{2}$ Muséum national d'Histoire naturelle, Département Systématique \& Evolution, UMS Taxonomie-Collections. \\ CP 51, 55 rue de Buffon, 75005 Paris, France. \\ ${ }^{3}$ Departamento de Zoologia, Universidade do Estado do Rio de Janeiro, Pavilhão Haroldo Lisboa da Cunha, Avenida São \\ Francisco Xavier 524, Maracanã, 20550-900 Rio de Janeiro, Rio de Janeiro, Brazil. \\ ${ }^{4}$ Corresponding author. E-mail: chcaetano@zipmail.com.br
}

\begin{abstract}
Gadila elongata comb. nov. was described in 1920 from the northern Gulf of Mexico. Until recently, it was only known from the type locality. Herein we present the first record of G. elongata from Brazil (Northeast coast, Ceará state, collected at $177 \mathrm{~m}$ ) and a morphometrics analysis of the Brazilian species of Gadila. A multivariate Discriminant Function Analysis, based on nine shell morphometric variables (length, maximum diameter, length to maximum diameter ratio, distance of point of maximum diameter from anterior aperture, maximum curvature, anterior aperture height to anterior aperture width ratio, apical aperture height, apical aperture width and apical aperture height to apical aperture width ratio) enabled the distinction between all species studied. Comparisons of shell morphometrics show that length and length to maximum diameter ratio are the most important variables in the differentiation of Gadila species.
\end{abstract}

KEY WORDS. Conchology; marine molluscs; morphometry; taxonomy.

Henderson (1920) described Cadulus elongatus based on an empty shell collected from the mouth of the Mississipi River $\left(29^{\circ} \mathrm{N}\right)$. Until the recent discovery of a specimen collected off the coast of Ceará (Northeast Brazil; $04^{\circ} \mathrm{S}$ ), C. elongatus was only known from the type locality. Upon close examination of the morphology of the specimen collected in Brazil, we propose that C. elongatus should be transferred to Gadila.

Gadila is represented by at least 63 recent species (STEINER $\&$ КАват 2004) that live on continental shelves and abyssal bottoms, with a worldwide distribution for the genus (SCARABINO 1995). The genus dates back to the Cretaceous (EMERson 1962) and is characterized by smooth, small- to medium-length, curved shells that reach their maximum diameter at the anterior third. The apex of the shell can be simple or have flattened lobes which may vary in number (SCARABINO 1995).

Five species of Gadila have been previously recorded from Brazilian waters (SCARABINO 1994, CAETANO et al. 2006): Gadila braziliensis (Henderson, 1920); G. dominguensis (d'Orbigny, 1853); G. pandionis (Verrill \& Smith in Verrill, 1880); G. pocula (Dall, 1889) and G. simpsoni (Henderson, 1920).

Here we present the first report of G. elongata comb. nov. from Brazilian waters, accompanied by a morphometric characterization of other congeneric species from Brazil.

\section{MATERIAL AND METHODS}

The material studied is derived from several oceanographic expeditions and was obtained from the following collections: (MORG) Museu Oceanográfico "Prof. Eliézer de Carvalho Rios", Fundação Universidade do Rio Grande, Rio Grande, Brazil; (MZUSP) Museu de Zoologia, Universidade de São Paulo, São Paulo, Brazil; (IBUFRJ) Departamento de Zoologia, Instituto de Biologia, Universidade Federal do Rio de Janeiro, Rio de Janeiro, Brazil; (UERJ) Departamento de Zoologia, Universidade do Estado do Rio de Janeiro, Rio de Janeiro, Brazil; (DOUFPE) Departamento de Oceanografia, Universidade Federal de Pernambuco, Pernambuco, Brazil; (CMPHRM) Coleção Malacológica "Prof. Henry Ramos Matthews", Universidade Federal do Ceará, Ceará, Brazil; (CRPC) Colin Redfern Personal Collection, Abaco, Bahamas; (ANSP) Academy of Natural Sciences, Philadelphia, USA; and (USNM) United States National Museum, Washington, D.C., USA.

This research is based on empty shells. Identification of the specimens was based on comparisons of shell morphology with type material and/or original descriptions and illustrations. Damaged shells were excluded from the morphometric analysis to avoid noise or imprecision in the data. Shell measurements 
were taken according to SHImek (1989), STeiner (1999), Steiner \& Linse (2000), Absalão \& de Paula (2004), including length (L), maximum diameter (Max), distance of point of maximum diameter from anterior aperture (Dmax), maximum curvature (Arc), distance of point of maximum curvature from the apex (Larc), anterior aperture height (Ha), anterior aperture width (Wa), apical aperture height (Hp), apical aperture width (Wp). The following ratios were calculated in order to assess the degree of shell slenderness and anterior and posterior aperture shape (L: Max; Ha: Wa; Hp: Wp, Larc: L). See Absalão \& de Paula (2004) for further discussion regarding the use of these ratios. To ensure independence among variables, we performed a preliminary correlation analysis among all variables, excluding those that showed strong correlation. A multivariate approach was carried out using Discriminant Function Analysis to integrate all morphometric data in a single analysis and a model was constructed with nine variables (L, Max, L: Max, Dmax, Arc, Ha: Wa, Hp, Wp and Hp: Wp). The variable Ha was excluded because it was highly correlated with other variables $(r>0.8)$. For the multivariate analysis, we standardized the morphometric data following RomesBURg (1984). All statistical procedures were performed using STATISTICA for Windows'99 Edition (Statistica 5.5) by StatSoft, Inc, Tulsa, Oklahoma.

\section{TAXONOMY}

\section{Gadila Gray, 1847}

Type species: Dentalium gadus Montagu, 1803, by original designation.

\section{Gadila elongata (Henderson, 1920) comb. nov. Figs 1-3}

Cadulus (Platyschides) elongatus Henderson, 1920: 122, pl. 19, fig. 15.

Polyschides elongatus: Steiner \& Kabat, 2004: 587.

Diagnosis. Shell medium (ca. $14 \mathrm{~mm}$ of length), exceedingly slender and evenly curved. Translucent bands alternating with white bands in fresh specimens, or all bands white. Shell diameter slightly increasing towards the maximum diameter. Maximum diameter at anterior fifth of shell. No evident swelling. Apex circular, slightly flat. Aperture oblique.

Taxonomic summary. Holotype USNM 323596. Type-locality: "off the mouth of Mississippi River, USBF, stn 2378, $29^{\circ} 14.30^{\prime} \mathrm{N}, 88^{\circ} 09.30^{\prime} \mathrm{W}, 68 \mathrm{fms}[124 \mathrm{~m}]^{\prime}$.

Additional material examined. Brazil, Ceará: (04¹4'S, $\left.37^{\circ} 12^{\prime} \mathrm{W}, 177 \mathrm{~m}\right), 1$ empty shell, 12.XI.2001, MNRJ 10482.

Distribution. USA: mouth of Mississippi River (HENDERSON 1920); Brazil: Ceará. Empty shells collected between 124 and 177 m (HeNderson 1920).

Remarks. The larger size and slender profile of the shell suggest that this species belongs to Gadila, not Polyschides (STEINER $\&$ KABAT 2004). Additionally, the absence of an apex divided into four lobes, characteristic of the holotype (Fig. 1) and the Brazil-

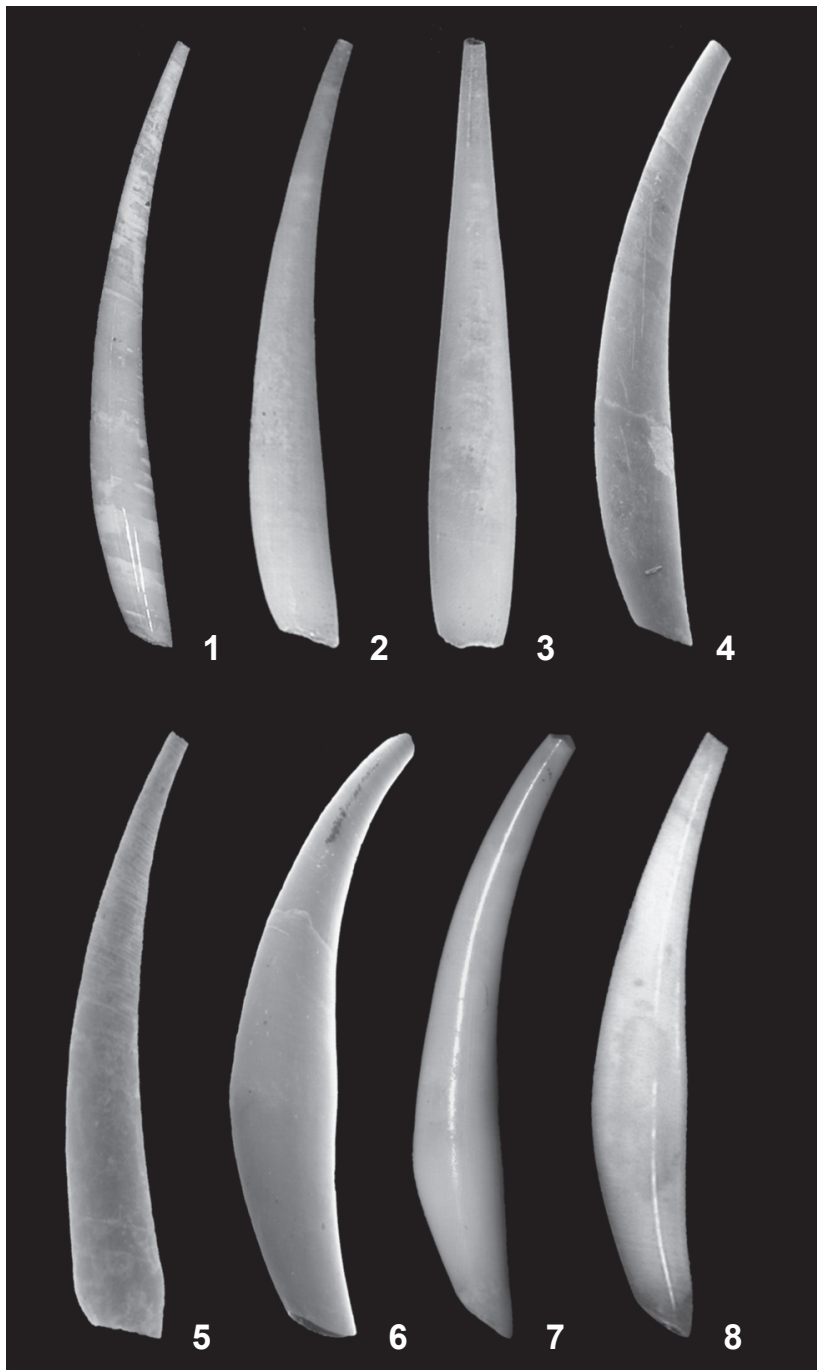

Figures 1-8. (1-3) Gadila elongata: (1) holotype USNM 323596, 14.1 mm; (2-3) MNRJ 10482, 13 mm; (4) G. braziliensis, IBUFRJ 3110, 10 mm; (5) G. dominguensis, IBUFRJ 9513, 8 mm; (6) G. pandionis, IBUFRJ 14314, 13 mm; (7) G. pocula, IBUFRJ 14312, 10 mm; (8) G. simpsoni, IBUFRJ 14317, $5 \mathrm{~mm}$.

ian specimen (Figs 2 and 3), reinforces the idea that its placement in Gadila is more appropriate. In the original description, HENDERSON (1920: 123) stated: "Apical characters are not clearly shown, but a slight flare of the rim with certain irregularities indicates a probable Platyschides affiliation". Since Platyschides was synonymized with Gadila by SCARABINO (1995), we conclude that our classification is consistent with Henderson's statement. Gadila braziliensis is characterized by a slender shell with a low expansion rate and a simple apex (Fig. 4). These characters are shared with $G$. dominguensis (Fig. 5) and G. elongata (Figs 1-3). G. braziliensis has a smooth external shell surface. 
By contrast, the shell surface of $G$. dominguensis is sculptured by transversal rings close to the apex. G. dominguensis also has a notable swelling in the shell, close to the anterior aperture. This feature is lacking in both G. braziliensis and G. elongata. Gadila elongata is also distinguished by having a longer (ca. 14 $\mathrm{mm}$ shell length) and markedly more slender shell. The other congeneric species treated in this paper, G. pandionis (Fig. 6), G. pocula (Fig. 7) and G. simpsoni (Fig. 8), have a more inflated shell with a notched apex.

The morphometric results obtained for the Gadila species are given in table I. Two species, G. elongata and G. pocula, are not included in these statistical comparisons because of the insufficient number of shells (only one specimen for each species).

The multivariate Discriminant Function Analysis distinguished between the four species: G. braziliensis, G. dominguensis, G. pandionis and G. simpsoni (Wilks' Lambda $=0.01 ; \mathrm{F}_{27,362}=$ $69.87 ; \mathrm{p}<0.0000$ ). This analysis correctly classifies nearly $97 \%$ of the specimens (Fig. 9), with only two out of 136 being incorrectly classified. The Discriminant Functions (FD) based on the raw coefficients of canonical variables are shown below:

$\mathrm{FD} 1=0.81 \mathrm{~L}+1.72 \mathrm{Max}+1.48 \mathrm{~L}: \mathrm{Max}-2.86 \mathrm{Dmax}-0.47 \mathrm{Arc}-$

$0.47 \mathrm{Ha}: \mathrm{Wa}+0.80 \mathrm{Hp}-1.62 \mathrm{Wp}-0.43 \mathrm{Hp}: \mathrm{Wp}$

FD2 $=1.08 \mathrm{~L}-0.92 \mathrm{Max}-0.62 \mathrm{~L}: \mathrm{Max}-0.60 \mathrm{Dmax}-1.01 \mathrm{Arc}+$

1.35Ha: Wa $-1.31 \mathrm{Hp}+1.06 \mathrm{Wp}+0.69 \mathrm{Hp}: \mathrm{Wp}$

FD3 $=-0.20 \mathrm{~L}-1.58 \mathrm{Max}-0.55 \mathrm{~L}: \mathrm{Max}+0.58 \mathrm{Dmax}+0.24 \mathrm{Arc}-$

$0.71 \mathrm{Ha}: \mathrm{Wa}+3.11 \mathrm{Hp}-3.07 \mathrm{Wp}-1.38 \mathrm{Hp}: \mathrm{Wp}$

The proportion of explicability was 0.74 for the FD 1 (= Discriminant Function 1), 0.19 for the FD 2 and 0.07 for the FD 3. Figure 9 plots only FD 1 vs. FD 2, giving a robust distinction

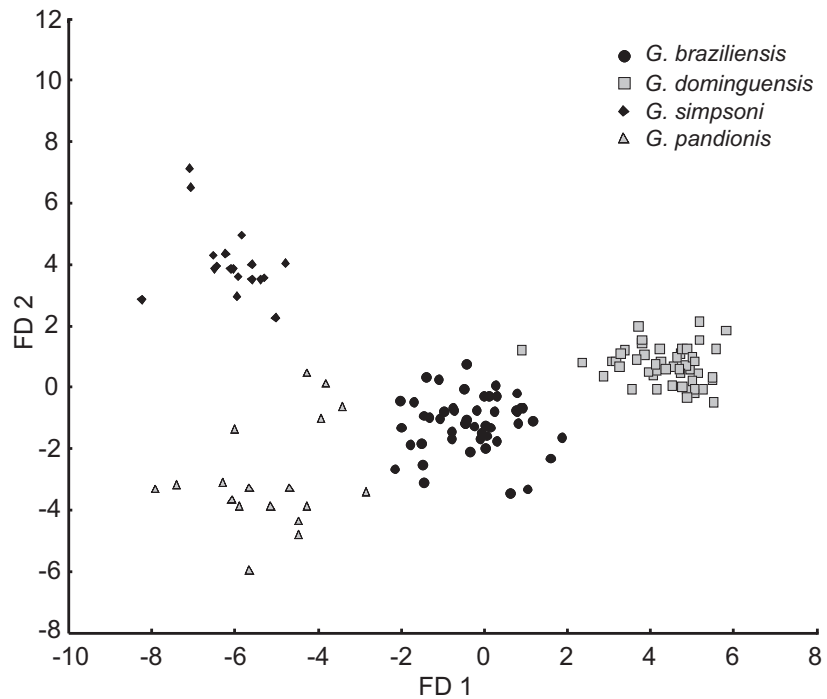

Figure 9. Results from Discriminant Analysis for the species of Gadila.

between the four species studied. The axis defined by FD 1 split the species into three groups. Gadila braziliensis presents intermediate values, distributed around positive and negative low values (between -2 and 2); G. dominguensis presents strongly positive values (between 2 and 6); while $G$. pandionis and $G$. simpsoni are characterized by strongly negative values (between -2 and -8$)$. On the other hand, the axis formed by FD 2 was able to separate $G$. simpsoni from the other three species, with the former being characterized by exclusively positive values.

Table I. Values of shell morphometric parameters for species of Gadila from Brasil. (L) Length, (Max) maximum diameter, (Dmax) distance of point of maximum diameter from anterior aperture, (Arc) maximum curvature, (Larc) distance of point of maximum curvature from the apex, $(\mathrm{Ha})$ anterior aperture height, $(\mathrm{Wa})$ anterior aperture width, $(\mathrm{Hp})$ apical aperture height, $(\mathrm{Wp})$ apical aperture width. All measurements are in millimeters. * Type dimensions obtained from HENDERSON (1920).

\begin{tabular}{|c|c|c|c|c|c|c|}
\hline \multirow{2}{*}{ Parmeters } & G. braziliensis $(\mathrm{n}=50)$ & G. dominguensis $(n=50)$ & G. elongata & G. pandionis $(n=16)$ & G. pocula & G. simpsoni $(n=18)$ \\
\hline & Mean $( \pm S D)$ & Mean $( \pm S D)$ & Type* & Mean $( \pm S D)$ & Type* & Mean $( \pm S D)$ \\
\hline $\mathrm{L}$ & $7.7(0.7)$ & $8.4(0.9)$ & 14.1 & $10.8(2.2)$ & 12.0 & $5.2(0.6)$ \\
\hline Max & $1.0(0.1)$ & $1.0(0.1)$ & 1.5 & $1.6(0.4)$ & 1.9 & $0.8(0.1)$ \\
\hline L: Max & $7.7(0.5)$ & $8.3(0.7)$ & & $6.6(0.5)$ & & $6.3(0.6)$ \\
\hline Dmax & $1.9(0.3)$ & $0.8(0.2)$ & & $3.7(0.8)$ & & $2.1(0.3)$ \\
\hline Arc & $0.5(0.1)$ & $0.4(0.1)$ & & $0.9(0.2)$ & & $0.2(0.0)$ \\
\hline Larc & $3.1(0.4)$ & $3.2(0.5)$ & & $4.3(1.0)$ & & $1.8(0.1)$ \\
\hline $\mathrm{Ha}$ & $0.6(0.0)$ & $0.7(0.1)$ & 1.4 & $1.0(0.2)$ & 1.4 & $0.5(0.0)$ \\
\hline Wa & $0.7(0.1)$ & $0.8(0.1)$ & 1.0 & $1.2(0.3)$ & 1.2 & $0.4(0.0)$ \\
\hline Ha: Wa & $0.8(0.1)$ & $0.9(0.0)$ & & $0.9(0.1)$ & & $1.3(0.1)$ \\
\hline $\mathrm{Hp}$ & $0.3(0.0)$ & $0.2(0.1)$ & 0.4 & $0.4(0.1)$ & 0.6 & $0.2(0.0)$ \\
\hline Wp & $0.3(0.0)$ & $0.2(0.0)$ & 0.4 & $0.5(0.1)$ & 0.6 & $0.3(0.0)$ \\
\hline Hp: Wp & $0.9(0.0)$ & $0.8(0.2)$ & & $0.7(0.0)$ & & $0.7(0.1)$ \\
\hline
\end{tabular}


In the FD 1, shell length to maximum diameter ratio (L: Max) seems to be the most important variable to distinguish species along this axis. There is a gradient of shell slenderness, with $G$. dominguensis being the most slender and G. pandionis and G. simpsoni, representing the more inflated shells. Gadila braziliensis occupies an intermediate position between these two extremes. The axis defined by FD 2, reflects the shell length and clearly separates $G$. simpsoni from the others species by its lower shell length.

Although the morphometric approach in Scaphopoda studies is relatively recent and rarely used, it has been useful in distinguishing among congeneric species (CaEtano \& AbSalÃo 2005, SCARABino \& CaETANo 2008). In groups such as Scaphopoda, with a limited number of conquiliological characters, the morphometric approach constitutes a valuable tool for making taxonomic decisions and its inclusion in subsequent works should be considered.

\section{ACKNOWLEDGEMENTS}

The first author wishes to thank the Fundação de Amparo a Pesquisa do Estado de São Paulo for a grant (FAPESP process 2008/03999-0). We thank Ellen Strong (USNM) for the photos of the holotype of G. elongata. Mike Sevens (Hawaii) for corrections to the English text.

\section{LITERATURE CITED}

Absalão, R.S. \& T. de Paula. 2004. Shell morphometrics of three species of gadilid Scaphopoda (Mollusca) from the Southwestern Atlantic Ocean: comparing the discriminating power of primary and secondary descriptors. Zootaxa 706: 1-12.

Caetano, C.H.S. \& R.S. Absalão. 2005. A new species of the genus Polyschides Pilsbry \& Sharp, 1898 (Mollusca, Scaphopoda, Gadilidae) from Brazilian waters. Zootaxa 871: 1-10.

Caetano, C.H.S.; V. Scarabino \& R.S. Absalão. 2006. Scaphopoda
(Mollusca) from the Brazilian continental shelf and upper slope ( $13^{\circ}$ to $\left.21^{\circ} \mathrm{S}\right)$ with descriptions of two new species of the genus Cadulus Philippi, 1844. Zootaxa 1267: 1-47.

Emerson, W.K. 1962. A classification of the scaphopod mollusks. Journal of Paleontology 36 (3): 461-482.

Henderson, J.B. 1920. A monograph of the east American scaphopod mollusks. United States National Bulletin 111: 1-177.

Romesburg, H.C. 1984. Cluster Analysis for Researchers. Belmont, Lifetime Learning Publications. XI+335p.

Scarabino, V. 1994. Class Scaphopoda, p. 305-310. In: E.C. Rios (Ed.). Seashells of Brazil. Rio Grande, Fundação Universidade do Rio Grande, $2^{\text {nd }}$ ed., 368p.

Scarabino, V. 1995. Scaphopoda of the tropical Pacific and Indian waters, with descriptions of 3 new genera and 42 new species. Mémoires du Muséum national d'Histoire naturelle 167: 189-379.

Scarabino, V. \& C.H.S. Caetano. 2008. On the genus Heteroschismoides Ludbrook, 1960 (Scaphopoda, Gadilida, Heteroschismoidinae), with description of two new species. The Nautilus 122 (3): 171-177.

SHImer, R.L. 1989. Shells morphometrics and systematics: a review of the slender, shallow-water Cadulus of the Northeastern Pacific (Scaphopoda: Gadilida). The Veliger 32: 233246.

Steiner, G. 1999. A new genus and species of the family Annulidentaliidae (Scaphopoda: Dentaliida) and its systematic implications. Journal of Molluscan Studies 65: 151-161.

Steiner, G. \& A.R. Kabat. 2004. Catalogue of species-group names of Recent and fossil Scaphopoda (Mollusca). Zoosystema 26 (4): 549-726.

Steiner, G. \& K. Linse. 2000. Systematics and distribution of the Scaphopoda (Mollusca) in the Beagle Channel (Chile). Mitteilungen aus dem Hamburgischen Zoologischen Museum und Institut 97: 13-30.

Submitted: 27.IV.2009; Accepted: 24.III.2010.

Editorial responsibility: Marcos Tavares. 